\title{
Sculpturing of the male breast
}

\author{
Kimit Rai FRCSC MBBS \\ The Rai Clinic, New Westminster, British Columbia
}

\begin{abstract}
K Rai. Sculpturing of the male breast. Can J Plast Surg 2001;9(1):33-36.
During the past decade, more esthetic surgery has been performed on male patients compared with the past. The most common request has been for improvements in the chest, 'love handles' and abdomen. In the youthful male, the musculature, breast tissue and nipple areolar complex are quite tight. As age progresses, laxity of the tissue, skin and musculature becomes a problem. Management of contouring of the male breast depends on the size and shape of the breasts, whether the breasts are glandular or fatty and whether ptosis is present. Surgery aims to reduce fat content, increase skin and subcutaneous tissue contracture, and reposition the tissue in a more anatomical plane. Most of the procedures done by the author have been by ultrasonic liposculpturing. The level of satisfaction has been over $90 \%$. A combination of ultrasound and conservative excision of glandular components can be done. Management of most juvenile breast hypertrophy and enlargement should be discouraged because of incomplete growth of the patient. However, sometimes ultrasound liposuction has a significant role to play in correcting this deformity.
\end{abstract}

Key Words: Gynecomastia; Ultrasonic liposculpturing

\section{Correction du sein chez l'homme}

RÉSUMÉ : Au cours de la dernière décennie, les hommes ont de plus en plus eu recours à la chirurgie esthétique. Les demandes les plus fréquentes avaient trait à des améliorations à la poitrine, aux «poignées d'amour» et à l'abdomen. Chez le jeune homme, la musculature, le tissu mammaire et le complexe mamelon-aréole sont assez fermes. Avec la progression de l' âge, la laxité des tissus, de la peau et de la musculature pose problème. Le traitement pour une définition plus nette du sein chez l'homme dépend de la taille et de la forme des seins, de la nature des tissus, glanduleux ou adipeux, et de la présence ou non de ptose. La chirurgie vise à réduire la teneur en tissus adipeux, à tendre la peau et les tissus sous-cutanés et à repositionner les tissus selon un plan plus anatomique. La plupart des interventions effectuées par l'auteur ont été faites par liposculpture aux ultrasons. Le taux de satisfaction a été de plus de $90 \%$. Une association d'ultrasons et d'excisions conservatrices des composantes glandulaires peut être effectuée. Le traitement de la plupart des hypertrophies mammaires juvéniles doit être déconseillé car la croissance n'est pas terminée chez ces patients. Par contre, dans certains cas, la liposuccion par ultrasons a joué un rôle significatif dans la correction de ces difformités.

$\mathrm{D}$ uring the past decade, more esthetic surgery has been performed on male patients compared with the past. Some forms of the media, such as magazines and journals, have promoted the need to look healthier and more youthful. Aging baby-boomers want a younger and healthier lifestyle, and are requesting esthetic improvement. Statistical data obtained from the American Society of Plastic Surgeons have shown an increase of approximately $200 \%$ in men who want esthetic surgery. The most common requests for improvement have been for the chest, 'love handles' and abdomen.

The masculine chest wall in a young male consists of a muscular base, a limited amount of breast tissue, a centrally based nipple areolar complex and tight skin. Aging, reduced physical activity and weight gain contribute to the reduction of muscle mass and tone, laxity of tissue and the development of a fatty, ptotic breast. For analytical purposes, classifications for lipodystrophy of the male breast are as follows: a pubertal breast, juvenile breast, youthful male breast, ptotic male breast, male breast after weight loss of $27 \mathrm{~kg}$ or more, post-hormonal therapy, and gynecomastia (ie, glandular male breast that can be in isolation in a teenager or in combination with lipodystrophy in obese patients) $(1,2)$.

Correspondence and reprints: Dr Kimit Rai, The Rai Clinic, Suite 405, 301 East Columbia Street, New Westminster, British Columbia V3L 3 W5.

Telephone 604-522-2925, fax604-522-1422, e-mail kimit_rai@telus.net 

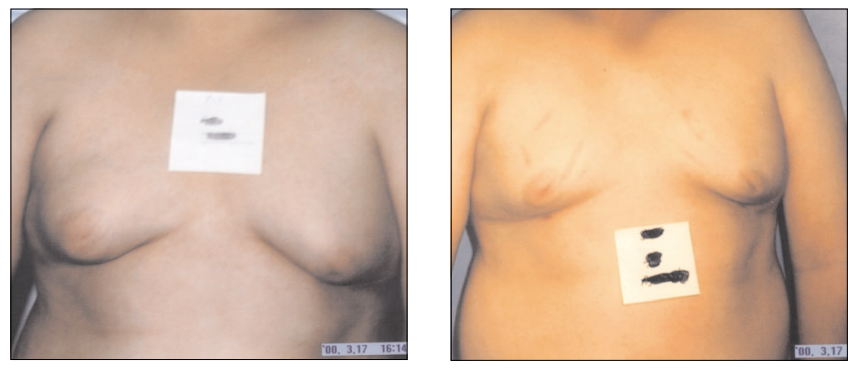

Figure 1) Thirteen-year-old man with grade 3 ptosis of the breasts. Left Before operation. Right After ultrasonic liposuction; $1500 \mathrm{~mL}$ of fat was removed from both breasts
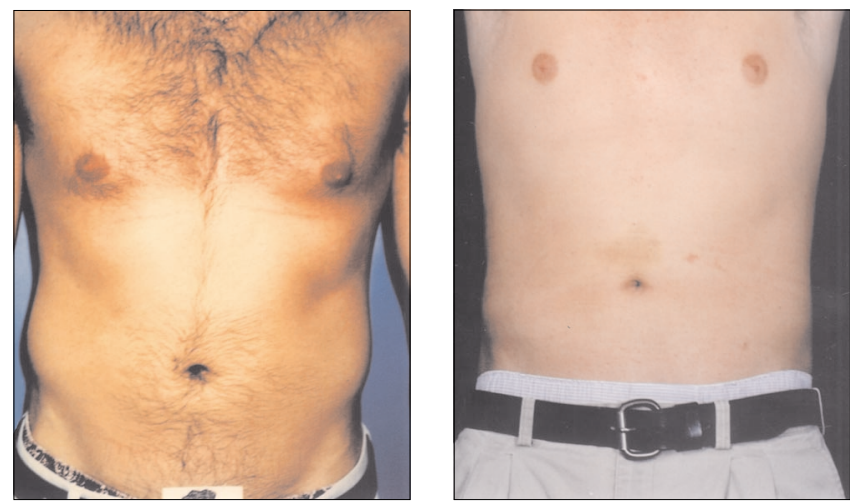

Figure 2) Twenty-year-old man with grade 1 ptosis and lipodystrophy of the abdomen. Left Before operation. Right Two months after ultrasonic liposuction; $1000 \mathrm{~mL}$ of fat was removed from the abdomen and $800 \mathrm{~mL}$ of fat was removed from the chest

For descriptive purposes, the classification of ptosis of the male breast is as follows:

- the nipple areolar complex is above the submammary crease (grade 1);

- the nipple areolar complex is at the submammary crease (grade 2); and

- the nipple areolar complex is below the submammary crease (grade 3).

The pathophysiology of ptosis consists of laxity of the pectoral tissue, including muscle and skin.

In a young man, the pectoral tissue is situated in the central part of the chest wall, where there is good muscle tone with taut skin. The nipple lies around the fourth and fifth intercostal space. Young men are body conscious and exercise to maintain their chest contour. Aging, weight gain and limited exercise contribute to the loss of muscle tone. In patients with gynecomastia, there is glandular breast enlargement underneath the nipple areolar complex. Gynecomastia may also be present in combination with obesity of the chest wall.

While examining a patient, the following factors need to be assessed for management and contouring of the male breast:

- size and shape of the breast;

- whether the breast is fatty or glandular;

- whether ptosis is present;
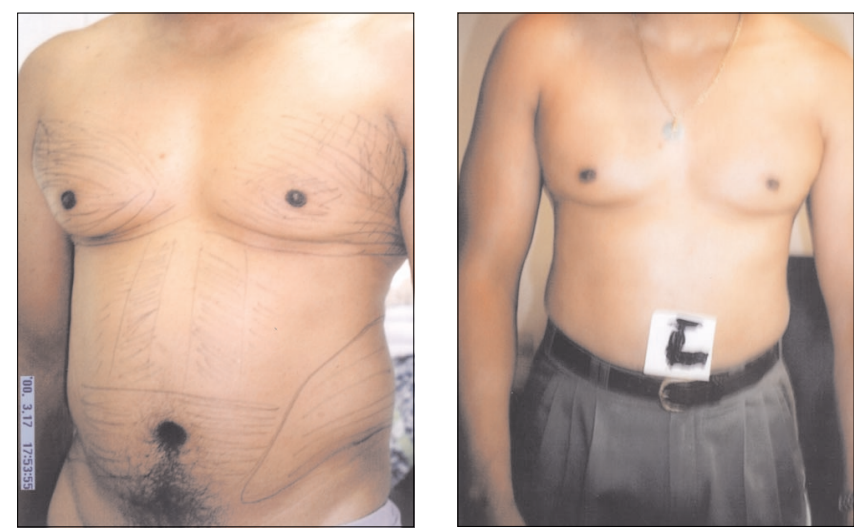

Figure 3) Thirty-five-year-old man with grade 2 ptosis of the breasts and lipodystrophy of the abdomen. Left Before operation. Right After ultrasonic liposuction; $1500 \mathrm{~mL}$ of fat was removed from both breasts and $1300 \mathrm{~mL}$ of fat was removed from the abdomen, through suprapubic incision

- whether the patient has had significant weight loss contributing to the laxity of tissue and ptosis;

- hormonal therapy given to patients with prostatic cancer; and

- whether steroids were used by the patient in the past.

\section{CASE PRESENTATIONS}

Six case reports of various contour deformities of the chest wall and their management are presented. Before surgery, all patients underwent endocrine studies, including pituitary, adrenal and testicular testing.

A 13-year-old pubertal man presented with lipodystrophy of the upper chest wall, including the breasts and upper abdomen. He had grade 3 ptosis of the breasts. Ultrasonic liposuction was performed. The total amount of fat removed from both breasts was $1500 \mathrm{~mL}$. The submammary crease was released by using ultrasound. Photographs before surgery and one month after surgery (Figure 1) are provided.

A 20-year-old man presented with lipodystrophy of the chest. He had grade 1 ptosis of the breasts and lipodystrophy of the abdomen. Through an abdominal incision, ultrasonic liposuction was performed. There was $800 \mathrm{~mL}$ of fat removed from the breasts, and $1000 \mathrm{~mL}$ of fat removed from the 'love handles'. Photographs of the patient before surgery and two months after surgery (Figure 2 ) are provided.

A 35-year-old man presented with lipodystrophy of the anterior chest and grade 2 ptosis of the breasts. He also had lipodystrophy of the abdominal wall. Ultrasonic liposuction was performed through an infra-areolar incision and suprapubic incision. A total of $1500 \mathrm{~mL}$ of fat was removed from the breasts. The submammary crease was released by using ultrasound on both sides. The 'love handles' were also reduced by using ultrasonic liposuction at the same time, and $1300 \mathrm{~mL}$ of fat was removed from the abdomen (Figure 3).

A 45-year-old man presented with lipodystrophy of the chest and abdomen, and grade 3 ptosis of the breasts. Ultrasonic liposuction was performed through an infra-areolar in- 

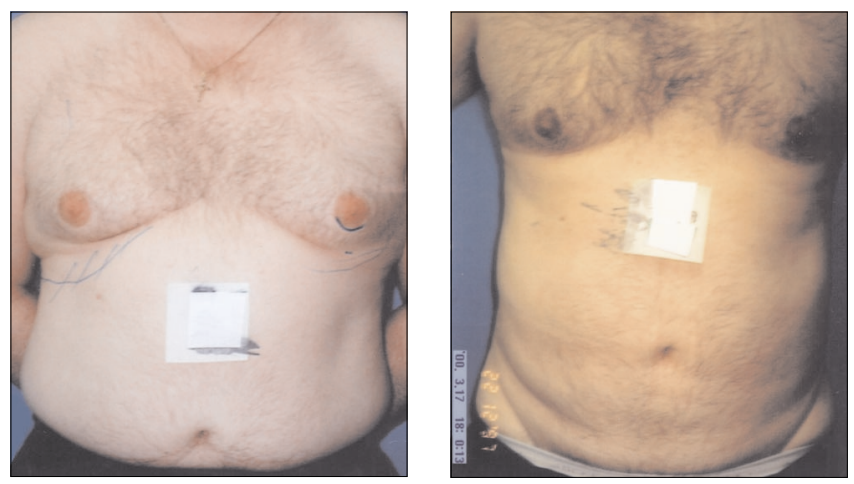

Figure 4) Forty-five-year-old man with lipodystrophy of the abdomen and chest, and grade 3 ptosis of the breasts. Left Before operation. Right After ultrasonic liposuction; $1000 \mathrm{~mL}$ of fat was removed from the abdomen through a suprapubic incision
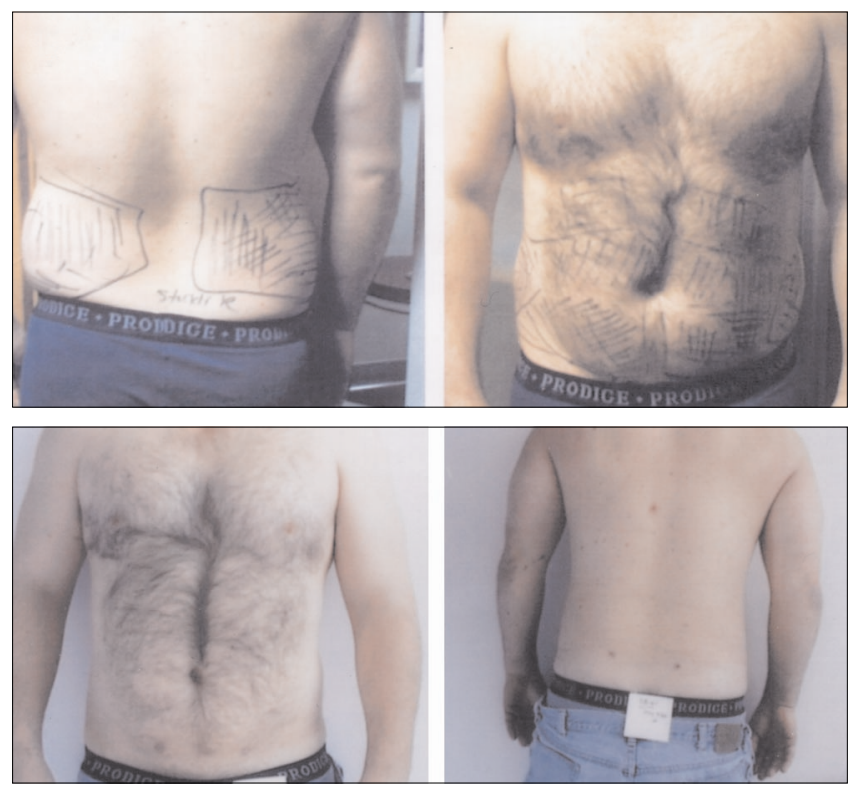

Figure 5) Forty-year-old man with grade 2 ptosis of the breasts and lipodystrophy of the abdomen. Top Before operation. Bottom After ultrasonic liposuction; $1500 \mathrm{~mL}$ of fat was removed from the abdomen through a suprapubic incision

cision and a suprapubic incision. A total of $1700 \mathrm{~mL}$ of fat was removed from the breasts and $1000 \mathrm{~mL}$ of fat was removed from the 'love handles' (Figure 4). The submammary crease was completely released by using an ultrasound probe and uretheral sound through the infra-areolar incision.

A 40-year-old man presented with grade 2 ptosis of both breasts, with lipodystrophy of the chest wall and abdomen. Ultrasonic liposuction was performed through two suprapubic incisions. A total of $1500 \mathrm{~mL}$ of fat was removed from the abdomen and $1500 \mathrm{~mL}$ of fat was removed from the chest (Figure 5). This was done through the suprapubic incisions only.

A male patient lost $27 \mathrm{~kg}$ of weight and presented with lipodystrophy of the chest. The patient had grade 3 ptosis of
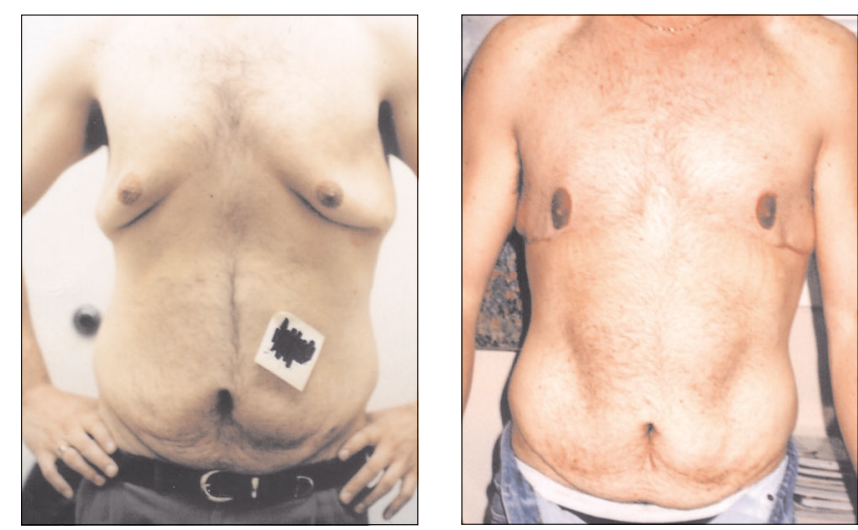

Figure 6) Adult man after $27 \mathrm{~kg}$ weight loss. Left Before operation. Right Six months after surgical excision of the breast tissue and free nipple graft

the breasts with atrophy of the tissue. Excisional surgery and free nipple grafting were performed (Figure 6).

\section{RESULTS}

Most patients complained of some burning sensation over the areas where ultrasound liposuction and liposculpturing were performed. The sensation lasted up to two months in some patients, and some associated numbness was also present. There were no cases of burns of the skin.

Patients who had a significant glandular element in their breast tissue were treated with a very conservative glandular excision, combined with ultrasound liposculpturing via the infra-areolar approach. In patients who also had ptosis of the breast, the submammary crease was released through the infra-areolar incision after completion of the ultrasound liposuction. This was done surgically with a pair of scissors, and in some situations a uretheral sound was used to separate the attachments of the fibres at the submammary crease, allowing the breast to float. This allowed the nipple areolar complex to be positioned higher with supportive garments in the postoperative phase.

Patients who had a combination of breast and abdominal wall sculpturing did exceptionally well, and they were the most pleased because of the change in the appearance of their torso, both posteriorly and anteriorly. In patients who had breast ptosis following extensive weight loss, excisional surgery similar to reduction mammoplasty was done but it left significant scarring on the chest wall. Although these patients were happy with the results, the scars were 'tell-tale' signs of the surgical procedure, and they were not very acceptable. In treating such patients, the authors recommend ultrasound liposculpturing with surgical release of the mammary crease and the application of supportive garments for six weeks. Patients should be reassessed in six months, and at that time, if ptosis of the breasts still persists, a circumareolar reduction, which leaves less scarring of the breasts and the results are more acceptable, should be performed. Therefore, such patients should be treated in two stages, with a six-month in- 
terval between surgeries. The following complications may occur.

- A second procedure may be required if there was an inadequate removal of fat.

- Nipple inversion may occur but can be minimized by using ultrasonic liposuction under the nipple.

- Scars may result if an excision is made.

- Paresthesia and numbness over the ultrasound site may occur, and can take up to two months to resolve.

\section{DISCUSSION}

Male breast contouring involves reduction of breast tissue, skin shrinkage with ultrasonic liposuction, repositioning of the nipple areolar complex after release of the submammary fold and, finally, an exercise program to increase the tone of the pectoralis major muscle. In post-weight loss patients, a second stage surgical procedure may be needed that may involve circumareolar mastopexy or some form of skin reduction that may leave significant scarring.

\section{CONCLUSIONS}

When a proper evaluation of the male breast is done, three elements are assessed: the muscle, the breast tissue, and skin and subcutaneous tissue. After classifying the level of tissue involvement, glandular enlargement and ptosis of the breast, the appropriate management can be executed. Ultrasound li- posculpturing alone, through the infra-areolar incision, has given a very high level of patient satisfaction. In patients who have grade 2 or 3 mammary ptosis, the submammary crease should be released, combined with ultrasound liposculpturing. If the glandular element is fairly large underneath the nipple areolar complex, a conservative excision of the infraareolar glandular tissue should be performed, combined with ultrasound liposculpturing. This reduces the time that the breast tissue is exposed to ultrasound liposuction and prevents postoperative nipple inversion.

In most patients with pubertal breast hypertrophy enlargement, surgical procedures should be discouraged. However, on some occasions, liposculpturing is the only option and has a significant role to correct this deformity. In patients with post-weight loss problems and significant ptosis, the operation should be performed in two stages. The first stage is liposculpturing, followed by the application of supportive garments for six weeks. The second stage involves reevaluating the patients after about six months to determine the need for a circumareolar mastopexy.

\section{REFERENCES}

1. Hage JJ, van Keserten PJ. Chest-wall contouring in female-to-male transsexuals: basic considerations and review of the literature. Plastic Reconstr Surg 1995;96:386-91.

2. Courtiss EH, Becker H, Rosenberg GJ, Siebert JW. Treatment of Gynecomastia. Aesthetic Surg 1994;Fall:4-9. 